\title{
O POETA DA VIDA MODERNA
}

Katia Muricy

Marco inquestionável da modernidade estética, Baudelaire proporciona inesperados fundamentos teóricos para importantes visões da modernidade na discussão filosófica contemporânea. A filosofia encontra uma teoria da modernidade em Baudelaire, lá onde ela é explicitamente enunciada, ou seja, nos textos estéticos e de crítica de arte, em especial, em $O$ pintor da vida moderna. Walter Benjamin, no entanto, fez uma consideração definitiva sobre a modernidade em Baudelaire: não é na obra teórica, mas na poesia, em As Flores do Mal, que ela se apresenta em toda a sua rica complexidade. Não é, tampouco, procurando nos poemas as características indicadas nos textos críticos que Benjamin irá encontrar a modernidade de Baudelaire. O encontro só se torna possível pela mortificação da sua poesia, isto é, por um procedimento característico da crítica alegórica de Walter Benjamin. É a partir do que se poderia chamar de uma reciprocidade alegórica entre o poeta e o crítico que se tornam visíveis todas as ricas implicações filosóficas da modernidade de Baudelaire.

Michel Foucault, em um de seus últimos escritos, em poucas, mas decisivas páginas, formula sua consideração privilegiada de Baudelaire como "uma das consciências mais agudas da modernidade". Para demonstrar a sua afirmação, recorre a um pequeno artigo de Kant e aos textos de crítica estética do poeta. Mais do que Kant ou Baudelaire, o que apresenta é a sua própria compreensão da modernidade. $\mathrm{Na}$ articulação Kant/ Baudelaire trata-se, para Foucault, de determinar uma possibilidade ética - a que chama de atitude - que, para muitos de seus leitores, representa uma virada no seu pensamento.

O belo artigo - "O que é o Iluminismo?" - foi publicado "What is Enligthenment?". Em Rabinow, P., The Foucault Reader. New York: Pantheon Books, 1984: 39.)

" (FOUCAULT, M. "Structuralisme et post-structuralis$\mathrm{me}^{\prime \prime}$. Em Dits et écrits, vol. IV. Paris: Gallimard, 1994: 431.)

-(FOUCAult, M. "Qu'est-ce que c'est l'Illuminisme?" Em MAGAZINE LITTÉRAIRE, $\mathrm{n}^{\circ}$ 207, Paris, abril 1984.) 
A questão do artigo gira em torno da resposta dada por Kant, em 1784, a um jornal berlinense, sobre o que seria o Iluminismo: "Was ist Aufklärung?" é um texto menor que sempre fascinou Foucault. ${ }^{1}$ A partir da resposta de Kant, Foucault apresenta a sua idéia de filosofia que, na versão americana, estende-se à compreensão de "vida filosófica". É no contexto da experiência vivida, de uma atitude pessoal específica, que Baudelaire é evocado. Esta atitude teria grandes afinidades com aquela que, determinando a originalidade do vínculo entre história, filosofia e atualidade, caracteriza a tarefa da filosofia como construção - na fórmula bem conhecida e, nem por isto, menos paradoxal - de uma "ontologia do presente".

Por volta dos anos 60 , quando a reflexão sobre a literatura era fundamental para o pensamento de Foucault, não deixa de ser curiosa a quase ausência de Baudelaire. Apresentada como o espaço de uma experiência radical dos limites da linguagem, a literatura foi privilegiada, ao menos durante os anos 1960, como um contra-discurso capaz de se opor à racionalidade moderna, acanhada nos limites de uma filosofia antropológica. Não há dúvidas de que a poesia de Baudelaire seria exemplar do caráter transgressor da literatura, tanto quanto ele é, como reconhecerá Foucault nos anos 1980, umas das mais requintadas consciências da modernidade.

É verdade que Foucault não deixa de se referir a Baudelaire, ainda que não se ocupe da obra do poeta. Em uma conferência de 1970, feita no Japão, La folie et la société, quando reafirma a aproximação insistentemente proposta nos anos 1960 entre literatura e loucura, Baudelaire é citado, juntamente com Nietzsche, como exemplo de que, para se abrir novos caminhos na literatura, é preciso ou imitar a loucura ou, de fato, enlouquecer. ${ }^{*}$ Retomando o tema em 1978, em uma edição ampliada dessa conferência, Foucault refere-se ao uso da droga em uma tradição literária que, de Edgar Allan Poe e Baudelaire, estende-se, em nossos dias, a Henri Michaux. . Considera que, se a articulação entre loucura e droga permitiu à literatura uma experiência da linguagem que a liberou de seus espaços institucionalizados, também revelou o seu estatuto marginal em nossa sociedade. Baudelaire, contudo, é aí apenas uma referência, e Foucault não se detém em mais nenhuma outra

\footnotetext{
${ }^{1}$ Uma primeira referência a esse texto encontra-se na introdução que Foucault escreveu, em 1978, à edição em inglês do livro de Georges Canguilhem, $O$ normal e o patológico, publicada posteriormente em francês com o título "La vie, l'experience et la science”. FOUCAULT, M. Em REVUE DE MÉTAPHYSIQUE ET DE MORALE, $\mathrm{n}^{\circ}$. 1, jan/mar, Paris, 1985: 3-14.
}

" (FOUCAULT, M. "La folie et la societé", Em Dits et écrits, vol. II. Paris: Gallimard, 1994: 132.)

"(FOUCAULT, M. "La folie et la societé". Em Dits et écrits, vol. III. Paris: Gallimard, 1994: 490.) 
('FOUCAULT, M. Les mots et les choses. Paris: Gallimard, 1966: 394.)

(FOUCAULT, M. "Le langage à l'infini". Em Dits et écrits, vol. I. Paris: Gallimard, 1994: 254.)
- (FOUCAULT, M. "Préface à la transgression. Hommage à Georges Bataille". Em Dits et écrits, vol. I. Op. cit.: 249.) consideração sobre ele, ainda que use a expressão "loucura artificial" referindo-se ao efeito literário da droga; o que não pode deixar de evocar, como um eco nítido, os "paraísos" do poeta.

Para Foucault, na década de 1960, a experiência filosófica contemporânea decidia-se no espaço de um diálogo emblemático, constituído pela pergunta de Nietzsche, sobre "quem fala", e pela resposta de Mallarmé - "A palavra fala". Isto equivale a dizer que a cena filosófica deslocara-se, em nossos dias, para o espaço da literatura, um "espaço mortal onde a linguagem fala de si mesma" Les mots et les choses anunciava um "retorno" da linguagem. Isto é, se, na episteme clássica, a linguagem diluíra-se na representação, agora, em seu novo modo de ser, ela se concentrava debruçando-se sobre si mesma, no movimento circular de um questionamento inesgotável dos seus próprios limites. A este movimento da linguagem corresponderia a "morte do homem" anunciada por Nietzsche, ou seja, de acordo com a leitura de Les mots et les choses, o esgotamento de uma tradição antropológica e humanista da reflexão filosófica. Esta tradição, inaugurada pela pergunta de Kant em sua Lógica "War ist der Mensch?" -, teria sido possível, nos termos da abordagem arqueológica proposta por Foucault, graças ao esfacelamento da ordem do discurso clássico que liberou a linguagem das amarras da representação. Desta quebra da episteme clássica surgiu uma filosofia essencialmente antropológica, cuja característica decisiva é a permanente oscilação entre o empírico e o transcendental. Nos termos da arqueologia, este seria o "solo" para as diferentes vertentes da filosofia moderna. O retorno da linguagem assinalaria o fim da filosofia moderna e também, ao que parece, um certo hiato na filosofia. Assim é que, nas páginas finais de seu belo livro, Foucault privilegia esse acontecimento como aquilo que "devemos mas ainda não podemos pensar". Para Foucault, o aniquilamento da subjetividade filosófica em uma linguagem que a deslegitima é característico do pensamento contemporâneo. Marca uma suspensão da palavra filosófica, um "embarras de parole", que indica, não certamente, o fim da filosofia mas, "talvez, do filósofo como forma soberana e primeira da linguagem filosófica”. * Se a filosofia ainda está presa à tradição antropológica, ou seja, se não consegue articular a novidade do acontecimento que Les mots et les choses anuncia, Foucault acredita encontrar na literatura a expressão de um pensamento radical: "Pergunto-me", escreve ele em 1963, na revista Tel Quel, "se não poderia se fazer ou, ao menos, esboçar-se à distância, uma on- 
tologia da literatura, a partir destes fenômenos de auto-representação da linguagem". * Para Foucault, na via oposta, tanto das consideraçōes historicizantes quanto das formalistas, a linguagem da literatura teria um ser, e a indagação sobre este ser que delimitaria o espaço do que há para se pensar em nossos dias: "o ser da literatura, tal como se produziu depois de Mallarmé e até nós, ocupa a região onde, depois de Freud, se faz a experiência da loucura". É, portanto, na literatura como expressão de uma experiência da linguagem que "diz o que não pode ser dito" que Foucault encontra uma "experiência do limite" que ele irá considerar sempre como sendo aquilo que a filosofia deve pensar.

É neste contexto, que tão decididamente privilegia a literatura, que a ausência de Baudelaire torna-se um problema para essas reflexões de Foucault sobre a literatura. Foucault propõe a tese de que a literatura seria, depois de Mallarmé, essencialmente alegórica. Sua linguagem teria, nela própria, o seu princípio de investigação: ela enunciaria simultaneamente o que diz e o código, isto é, a língua de sua decifração. Neste movimento, a crítica torna-se uma instância intrínseca à obra de arte literária, não como uma consideração exterior a ela, mas como parte da própria obra, necessária ao novo modo de ser da linguagem; esse ir e vir reflexivo da palavra à língua. Analisando a literatura de Raymond Roussel, por exemplo, Foucault distingue, nesta perspectiva, o ideal clássico de estilo, do modo de ser da linguagem na obra literária moderna. No ideal clássico, há "sob a necessidade soberana das palavras empregadas, a possibilidade, ao mesmo tempo mascarada e designada, de dizer a mesma coisa mas de forma diferente". Na modernidade literária ocorre o contrário: "toda a linguagem de Roussel procura dizer, sub-repticiamente duas coisas com a mesma palavra". A afirmação do caráter alegórico da literatura contemporânea fica reforçada pela consideração da dimensão da escrita, característica do novo modo de ser da linguagem que "suspendia o reino da língua em um gesto atual da escrita”.

Para Foucault, o gesto inaugural desse novo espaço é de Mallarmé, e Roussel é o precursor da modernidade literária expressa nas obras de Antonin Artaud, de Pierre Klossowski, de Maurice Blanchot, de Georges Bataille, de Kafka. Baudelaire, o "poeta das alegorias", que tão exemplarmente incorporou a dimensão da crítica à produção da obra de arte, construindo a modernidade estética em sua lírica mais do que a definindo em seus ensaios, fica fora desse 
(FOUCAULT, M. "Le langage à l'infini". Op. cit.: 253.) novo "modo de ser da linguagem literária". Na perspectiva arqueológica, a exclusão é uma conseqüência necessária. Atribuir ao poeta uma excepcionalidade, como a atribuída a Nietzsche, comprometeria a integridade dos blocos epistêmicos propostos em Les mots et les choses. Por outro lado, fica difícil, mesmo impossível, pretender que a poesia de Baudelaire corresponda ao ideal clássico de estilo definido por Foucault. Só resta ao leitor imaginar que, sem os constrangimentos impostos pelo caráter sucessivo das rígidas figuras epistêmicas recortadas em Les mots et les choses - que determina a necessidade desse corte inaugural em Mallarmé sob o risco de comprometer a argumentação arqueológica -, Foucault poderia conceber uma historicidade das obras de arte e da literatura capaz de estabelecer conexões não cronológicas e não lineares entre estas. Em um belo artigo de 1963, Le langage à l'infini, Foucault parece vislumbrar tal possibilidade, formulando o projeto daquela "ontologia da literatura" que, certamente, pelos exemplos dados, poderia construir essas conexões no movimento de auto-representação da linguagem: "A reduplicação da linguagem, ainda que secreta, é constitutiva de seu ser enquanto obra, e os signos que dela podem aparecer devem ser lidos como indicaçôes ontológicas". *

Assim, a noção de alegoria poderia se revestir deste caráter ontológico e proporcionar toda a sua riqueza interpretativa para a análise das obras de arte e literárias que são autônomas e detentoras de uma temporalidade específica não submetida à redução dos recortes epistêmicos lineares. Mais ainda, poderia se constituir, explicitamente, como um procedimento crítico nas análises de Foucault. Nos anos 1930, Walter Benjamin já indicara a alegoria, que desconstrói o contexto simbólico e multiplica os sentidos da obra, como o modo da crítica moderna. Já foi observado, com muita pertinência, que Foucault interpreta alegoricamente e quer, ao mesmo tempo, contraditoriamente, evitar os efeitos pluralizantes do procedimento alegórico propondo a sua interpretação como uma descrição "objetiva". A sua famosa leitura do quadro de Velasquez, em Les mots et les choses, seria um exemplo deste procedimento alegórico não assumido em todas as suas produtivas conseqüências. ${ }^{2}$

\footnotetext{
${ }^{2}$ José A. Bragança de Miranda considera: "Ao não explicitar a alegoria, contrariamente a Walter Benjamin, Foucault tende a dominar a alegoria através do simbólico, mas para isso é obrigado a controlar os efeitos da alegoria, afirmando-a como única, como real. Mas isso é aporético. As suas análises tendem a apresentarse como descrições, como "objetivas", quando ele explicitamente recusa a "objetividade”. (...) O problema é que, retoricamente, a argumentação estética tende a
} 
Também quando indica o caráter alegórico da literatura que se debruça sobre o novo ser da linguagem, Foucault não acolhe a contrapartida alegórica na sua leitura.

Pode ser este um dos motivos de seu silêncio a respeito da obra poética de Baudelaire, que, nos brilhantes ensaios sobre literatura dos anos 1960, fica esquecida em algum limbo intermediário entre a ordem da representação e o retorno da linguagem, inacessível à tematização arqueológica. Talvez seja por isso também que, quando finalmente é reconhecida a sua importância, esta se deva exclusivamente a seus ensaios estéticos e não a sua poesia, no entanto muito mais importante para a compreensão da riqueza da concepção de modernidade do poeta.

Walter Benjamin, em seus clássicos estudos sobre Baudelaire, escritos nos anos 1930, demonstrara como a mais alta visão da modernidade é construída, não nos ensaios estéticos, mas em As Flores do Mal. Assim, os textos com os quais Foucault se ocupou, " $O$ pintor da vida moderna" " "Sobre o heroísmo da vida moderna", estariam longe de fazer justiça à visão da modernidade da obra lírica, construída a partir de uma concepção de tempo bem mais complexa do que a proposta nos ensaios. Nos poemas, imagens carregadas de uma temporalidade que articula simultaneamente o passado e o presente, a morte e o novo, apresentam-se no espaço irônico da alegoria para a construção de um heroísmo do presente, de uma experiência moderna. $\mathrm{O}$ jogo de liberdade com o real, que implica esta construção do presente e de si, não pode ter lugar na sociedade ou na política. A atitude moderna, Foucault reconhece, só pode ser vivida no espaço da literatura, no espaço da arte. De qualquer forma, Foucault não irá entrar neste espaço: apesar do elogio tardio a Baudelaire, a literatura, em 1984, já não está, há muito, em seu horizonte de interesses. No entanto, sabe-se a importância que ela teve para Foucault.

A aproximação de Kant e Baudelaire, nos anos 1980, responde às injunçōes de seu próprio pensamento. Foucault apresenta a

apagar os traços da alegorese que pratica, perdendo a aposta contida no princípio de que "il faut feindre de ne pas savoir". Tal fingimento implicaria que se conseguisse esquecer o próprio fingimento, chegando junto de cada quadro, de cada obra, de cada ato como se fosse a primeira vez. Foucault não abole esta possibilidade, debate-se com ela, bate-se por ela. Em Les mots et les choses perdeu. Sabia que fingia, mas esqueceu-se que o sabia". MIRANDA, J.A.B "Foucault e Velásquez: a função do argumento estético em Foucault". "Michel Foucault, uma analítica da experiência”. Em REVISTA DE COMUNICAÇÃO E LINGUAGENS, vol. 19. Lisboa: Edições Cosmos, 1993: 47-67. 
- (FOUCAULT, M. "What is Enligthenment?" Op. cit.: 39.) questão da Aufklärung enfatizando o seu caráter de decisão da vontade, como uma atitude individual, um trabalho sobre si. É neste contexto de compreensão da modernidade como uma atitude face ao presente que Baudelaire ganha uma posição emblemática. Foucault lê Kant como que pela lente de Baudelaire: antes mesmo de ser nomeado, o poeta parece orientar a leitura. Nesta leitura, a $A u-$ fklärung não é um recorte histórico, nem o desenvolvimento moral progressivo da humanidade, mas a novidade de uma atitude do filósofo face à atualidade. Para que esta leitura - que gostaria de chamar de alegórica - fosse possível, Foucault não só privilegiou radicalmente um texto menor, como o descontextualizou em relação a textos mais importantes de Kant, como "A idéia de uma história universal de um ponto de vista cosmopolita", do mesmo ano do artigo do jornal berlinense; ou como "O conflito das faculdades", no entanto analisado por ele no curso de 1983. Ainda mais, descontextualizou conceitos usados por Kant no artigo, como o de vontade, em benefício da concepção de Iluminismo e de modernidade, que quis fazer prevalecer para a sua proposta da filosofia como "ontologia do presente". Kant propõe a Aufklärung como uma modificação na relação entre vontade, autoridade e uso da razão. Foucault irá enfatizar aquela maneira, que ele qualifica de "quase negativa", pela qual Kant caracteriza a Aufklärung como a saída da "menoridade", pelo pleno uso da razão. $\mathrm{O}$ aude sapere, o "ousa saber" kantiano, explicita, para Foucault, a Aufklärung e a modernidade como a exigência de uma mudança pessoal, de um trabalho sobre si, isto é, "um ato de coragem a ser efetuado pessoalmente".

Para caracterizar a atitude moderna, a coragem do aude sapere kantiano, ou seja, para apresentar a sua própria concepção da modernidade como um gesto concreto e pessoal do filósofo, Foucault toma o exemplo "quase necessário" de Baudelaire, "reconhecidamente uma das consciências mais agudas da modernidade no século XIX". "A modernidade de Baudelaire, para Foucault, referese primeiramente a uma atitude em relação à percepção do tempo. A característica atribuída habitualmente à modernidade - a consciência da descontinuidade do tempo relacionada à ruptura com a tradição, à erupção da novidade e à experiência de fugacidade dos acontecimentos - não basta para se compreender a modernidade de Baudelaire. Se o poeta a define como "o transitório, o fugidio, o contingente", a atitude moderna que Foucault encontra em Baudelaire é aquela que o leva, não simplesmente a constatar e se con- 
tentar com esta apreensão da descontinuidade do tempo, mas, ao contrário, a que exige uma tomada de posição que, de certo modo, se opõe a essa transitoriedade. Consiste em construir, por uma decisão da vontade, uma eternidade muito particular. Este conceito de eterno não busca eleger uma atemporalidade, projetada no passado ou no futuro, mas se circunscreve no instante presente.

A modernidade de Baudelaire seria a de não aceitar o curso do tempo e, por uma atitude voluntária, propor-se a construí-lo, submetendo-o a este ato de vontade. É por esta decisão da vontade que Baudelaire irá alcançar o "heróico". A modernidade de Baudelaire não seria apenas uma sensibilidade ao presente transitório, fugidio, mas uma decisão, uma atitude firme de "heroificar" o presente.

Foucault define o trabalho do filósofo moderno como semelhante ao do artista moderno de Baudelaire: "Pela atitude de modernidade, o alto valor do presente é indissociável do esforço furioso para imaginá-lo de forma diferente e para transformá-lo, não pela sua destruição, mas pela captura do que ele é. A modernidade baudelairiana é um exercício onde a extrema atenção ao real é confrontada com a prática de uma liberdade que é, ao mesmo tempo, respeito e violação deste real”. *

$\mathrm{O}$ aude sapere kantiano ganha, juntando-se à atitude de Baudelaire, a feição que permite não só reconhecer os limites do que, na nossa atualidade, se pode pensar, fazer e esperar mas também ironizar esses limites: poder pensar, agir e sentir para além deles. $\mathrm{O}$ presente, carregado de possibilidades, pode ser objeto de uma construção, o que determina também uma mobilidade em suas relações com o passado.

Baudelaire concebia a modernidade como algo mais do que uma relação específica com o presente. Concebia-a também como uma forma de relação que se deve construir consigo mesmo. Esta forma moderna de relacionar-se consigo mesmo é o ascetismo. $\mathrm{O}$ eu moderno, em conseqüência mesmo da atitude de construção do tempo, é também objeto de uma construção. Há, em Baudelaire, uma recusa em aceitar o $e u$ por assim dizer natural que existe no fluxo dos momentos. Este esforço árduo de construção de si é chamado por Baudelaire de dandismo. $\mathrm{O}$ ascetismo do dândi, "de seu corpo, de seu comportamento, de seus sentimentos e paixões, faz de sua existência uma obra de arte”. Foucault escreve, aludindo mais uma vez ao seu próprio projeto filosófico, que o homem moderno,
"(FOUCAULT, M. "What is Enligthenment?" Op. cit.: 41.) 
(BENJAMIN, Walter. "Paris do Segundo Império". Em Charles Baudelaire: um lírico no auge do capitalismo. Obras escolhidas III. São Paulo: Editora Brasiliense, 1989: 81.) para Baudelaire, não é o que parte para a descoberta de si mesmo, de seus segredos e de sua verdade escondida; é o que procura inventar-se a si próprio. Esta modernidade não "libera o ser próprio do homem"; ela o obriga à "tarefa de elaborar-se a si próprio".

O Baudelaire que, em Foucault, "corrige" o Kant da história universal não é, portanto, nem o cético do progresso, nem o "haschischin" do Hôtel Pimodan ou, tampouco, o rebelde que durante as barricadas descia às ruas de Paris gritando contra o padrasto, "Abaixo o general Aupick". É o artista na construção conscientemente crítica de sua obra. No entanto, é justamente esta dimensão que parece se perder na breve análise que faz Foucault da modernidade de Baudelaire. Limitando sua leitura aos ensaios estéticos, escapou a Foucault a compreensão infinitamente mais rica da modernidade em Baudelaire: a que ele constrói nas alegorias de As Flores do Mal e que parece corresponder, com perfeição, àquela exigência feita por Foucault ao pensamento atual: a de propor "uma maneira de viver diferentemente o tempo". ${ }^{3}$

Se nos anos 1960, quando a literatura era uma dimensão privilegiada no pensamento de Foucault, a modernidade da poesia alegórica de Baudelaire lhe escapou nos balizamentos impostos pelo projeto arqueológico, nos anos 1980, tendo se eclipsado esse privilégio em benefício da "experiência concreta", temas como a "construção do presente" e a "construção de si" ficaram, na apresentação de Baudelaire, restritos ao tom programático dos ensaios estéticos, muito aquém do gesto heróico do poeta que se deu no espaço de sua incomparável poesia.

Para Benjamin, ao contrário, é na poesia - esta que, segundo ele, usando a expressão de Nietzsche, "paira no céu do Segundo Império "como um astro sem atmosfera" - que se encontra a visão mais aguda da verdadeira natureza da modernidade: "a teoria da arte moderna é, na visão baudelairiana da modernidade, o ponto mais fraco".* Mais do que a consciência da modernidade do poeta, interessa a Benjamin analisar a sua poesia como a mais rica expressão das transformaçóes da estrutura da experiência na modernidade. Interessa-lhe a estratégia poética muito precisa de As Flores do $M a l$, que realiza a tarefa de articular as vivências desgarradas da

\footnotetext{
${ }^{3}$ Em muitos momentos da sua obra, Foucault se refere a essa necessidade. A fórmula é famosa: "É preciso, hoje mesmo, viver de forma diferente o tempo". FOUCAULT, M. "Vivre autrement le temps". Em Dits et écrits, vol. III. Op. cit.: 790 .
} 
modernidade em uma autêntica experiência lírica. É este conteúdo que confere à obra "uma assinatura única" e a torna "o exemplo mais extraordinário do comportamento heróico em Baudelaire". Baudelaire resolveu, na sua lírica, o que constituía o impasse teórico de seus ensaios, isto é, a relação entre o eterno e o contingente, entre o clássico e o histórico, o antigo e o moderno. Nos ensaios, a beleza moderna é a particularização de algo eterno e absoluto, e este absoluto está na antiguidade. $\mathrm{O}$ artista moderno deverá saber "extrair da moda o que ela pode conter de poético no histórico"; arrancar o eterno do transitório. No entanto, não se encontra aí aquela relação decisiva entre a modernidade e a antiguidade que a sua poesia estabelece: “... nenhuma das reflexōes estéticas (...) expõe a modernidade em sua interpenetração com a antiguidade como ocorre em certos trechos de As Flores do Mal.

O tema, tão caro a Foucault, da heroificação como atitude moderna - explicitado por Baudelaire no axioma de sua teoria da modernidade: "O herói é o verdadeiro objeto da modernidade" ganha a sua dimensão mais rica na poesia, no contexto dessa relação com a antiguidade que determina a sua apreensão do moderno. O heroísmo em Baudelaire consiste em impor à poesia construir a modernidade como algo clássico. E isto é o que alcança em As Flores do Mal. Benjamin sugere uma aproximação, a meu ver, mais rica do que aquela com Kant, proposta por Foucault, entre o poeta e Nietzsche: ambos teriam compreendido a essência da arte moderna na relação antiguidade/ modernidade. Comentando a obra de Wagner em $O$ nascimento da tragédia, Nietzsche afirmara: "Se Wagner, na escolha de seus temas e no seu proceder dramático, se aproxima da antiguidade, torna-se, graças à sua força de expressão apaixonada, o representante mais importante da modernidade".*

O moderno em Baudelaire é uma construção de novas relações com o passado. Seu "caráter destrutivo" manifestava-se naquela atitude que Proust chamou de um "estranho seccionamento do tempo" e que Benjamin relaciona ao desejo do poeta de "interromper o curso do mundo".

Já foi observado que, através de Baudelaire, Benjamin não cessa de falar de si próprio. Seus clássicos ensaios sobre o poeta respondem às exigências de elaboração de seu próprio pensamento. Ecoam em sua leitura as preocupações em torno de uma teoria do tempo e da história, que já elaborara no livro sobre o drama barroco alemão, e projetam-se a partir dela formulações que apresen-
* (BENJAMIN, W. "Parque Central" Em Charles Baudelaire: um lírico no auge do capitalismo. Obras escolhidas III. Op. cit.: 168.)

* (BENJAMIN, W. "Paris do Segundo Império". Op. cit.: 81.$)$

"(Citado por BENJAMIN, W. "Paris do Segundo Império". Op. cit.: 80.)

"(BENJAMIN, W "Parque Central". Op. cit.: 160164.) 
tará na seção epistemológica do livro sobre as Passagens e nas teses "Sobre o conceito da história" ${ }^{4} \mathrm{O}$ modelo de temporalidade que Benjamin propõe é o das obras de arte que, ao surgirem, determinam uma ruptura com o passado capaz de inaugurar a sua própria tradição. Esta tematização está no cerne da concepção de origem exposta em Origem do Drama Barroco Alemão. Benjamin encontra na poesia de Baudelaire a interpretação capaz de conectar elementos simultaneamente atemporais e históricos que possibilitam construir a experiência da modernidade: "Uma interpretação (...) faz jorrar conexões que são atemporais, sem serem, por isto, desprovidas de importância histórica”. Esta compreensão de interpretação é que fundamenta também a sua compreensão de crítica, delimitada, no prefácio do livro sobre o drama barroco, como questão filosófica. No âmbito das idéias - eliminada a noção de sujeito-objeto e, conseqüentemente, a questão do método como garantia da certeza -, a interpretação, atenta à temporalidade intensiva das idéias e obras de arte, propóe-se a estabelecer elos intensivos, capazes de arrancar a obra da repetição a que lhe condenara a continuidade da tradição, para lhe dar uma nova origem no presente da leitura. É o que faz Benjamin com a poesia de Baudelaire: ele a arranca da recepção de uma história linear da literatura para inaugurá-la como origem na idéia de modernidade.

As correspondances e as alegorias são, em As Flores do Mal, as armas na estratégia de construção da experiência da modernidade, na perspectiva dessa relação com a antiguidade. $\mathrm{O}$ conceito de correspondance é, na poética de Baudelaire, responsável por uma outra forma de relação com o passado a que Benjamin chamou de rememoração (Eingedenken): "As Correspondances são os dados do rememorar.” Despindo o conceito de seu invólucro místico originário, Baudelaire fez dele o fundamento de uma experiência pro-

\footnotetext{
${ }^{4}$ A construção de uma experiência lírica a partir da exigência de tornar épica a modernidade determina, em Baudelaire, uma concepção do tempo decisiva para o pensamento de Benjamin. A importância desta influência pode ser avaliada, por exemplo, na sua fundamental noção de imagem dialética: "Não se deve dizer que o passado ilumina o presente ou que o presente ilumina o passado. Uma imagem, ao contrário, é onde o Antigo encontra o Agora em um raio para obter uma constelação. Em outras palavras, a imagem é a dialética parada. Porque, enquanto a relação do presente com o passado é puramente temporal, contínua, a relação do Antigo com o Agora é descontínua. Somente as imagens dialéticas são imagens autênticas (...) e o lugar onde são encontradas é a linguagem". BENJAMIN, W. Das Passagen-Werk Gesammelte Schriften, V, Frankfurt am Main: Suhrkamp Verlag, 1982, Na 3.
} 
priamente moderna, tal como a constrói em sua lírica. Recortadas da continuidade temporal, essas rupturas significativas constituirão uma outra forma de memória. Sobre esses dias descontínuos, Benjamin observa: "São dias do rememorar. Não são assinados por qualquer vivência. Não têm qualquer associação com os demais: antes, se destacam no tempo"*

Arrancados do esquecimento, estes dias eleitos são também salvos da reclusão no espaço privado da memória individual. A rememoração os abriga em um outro espaço - a esfera do culto, deslocada por Baudelaire para a arte, isto é, para o culto do belo. Pelas correspondances, uma outra relação temporal com o passado permite uma experiência autêntica, isto é, comunitária, na época das vivências isoladas:

As correspondances cristalizam um conceito de experiência que engloba elementos cultuais. Somente ao se apropriar desses elementos é que Baudelaire pode avaliar inteiramente o verdadeiro significado da derrocada que testemunhou em sua condição de homem moderno. Só assim, pôde reconhecê-la como um desafio destinado a ele, exclusivamente, e que aceitou em As Flores do Mal (...). O significado que as correspondances têm para Baudelaire pode ser definido como uma experiência que se procura estabelecer ao abrigo de qualquer crise. E somente na esfera do culto ela é possível. Transpondo este espaço, ela se apresenta como "o belo". Neste, o valor cultual aparece como um valor da arte.

As correspondances querem trazer, para a consciência sobressaltada pelos choques, a experiência de um passado que Benjamin chama de pré-histórico. Baudelaire o nomeia como "vida anterior", "antiguidade". Spleen et Idéal, o primeiro conjunto de poemas de As Flores do Mal, ilustra a atualização do "passado pré-histórico" pela rememoração:

O idéal insufla a força do rememorar; o spleen lhe opõe a turba dos segundos. Ele é o seu soberano e senhor, como o demônio é o senhor das moscas.(...) No spleen, o tempo está reificado: os minutos cobrem o homem como flocos de neve. (...) No spleen, a percepção do tempo está sobrenaturalmente aguçada; cada segundo encontra o consciente pronto para amortecer o seu choque."

Baudelaire articula spleen e idéal em uma tensão na qual o idéal incita à rememoração, sem que por ela consiga pôr fim ao sentimento do spleen. A persistência melancólica é acompanhada de uma inconsolável impotência. $\mathrm{O}$ verso "Le printemps adorable a perdu son odeur", do poema "Le gôut du néant", é o lamento desta impotência:
"(BENJAMIN, W. "Sobre alguns temas em Baudelaire". Em Charles Baudelaire: um lírico no auge do capitalismo. Obras escolhidas III. Op. cit.: 131.)

" (BENJAMIN, W. "Sobre alguns temas em Baudelaire". Op. cit.: 132.)

" (BENJAMIN, W. "Sobre alguns temas em Baudelaire". Op. cit.: 135-136.) 
- (BENJAMIN, W. "Sobre alguns temas em Baudelaire". Op. cit.: 135.)

(BENJAMIN, W. "Sobre alguns temas em Baudelaire". Op. cit.: 141.)

(BENJAMIN, W. "Paris do Segundo Império" Op. cit.: 80)
Neste verso, Baudelaire afirma algo extremo com extrema discrição; e isto o torna inconfundivelmente seu. $\mathrm{O}$ desmoronamento da experiência que ele, um dia, havia compartilhado é confessado na palavra perdeu (...) Se, mais do que qualquer outra lembrança, o privilégio de confortar é próprio do reconhecer um perfume, é talvez porque embota profundamente a consciência do fluxo do tempo. Um odor desfaz anos inteiros no odor que ele lembra. Isto faz desse verso de Baudelaire um verso insondavelmente inconsolável. Não há nenhum consolo para quem não pode mais fazer qualquer experiência.*

Seu heroísmo é ter-se dado como tarefa "elevar (a vivência) à categoria de verdadeira experiência", ter-se imposto fazer com que "olhos que haviam, por assim dizer, perdido a capacidade de olhar" pudessem ver a "beleza moderna". A heroificação em Baudelaire será irônica, tanto quanto é precário o clássico moderno. A modernidade quebra a tradição e, ao mesmo tempo, problematiza-se como tradição virtual. É no espaço da ironia e da paródia que o poeta articula modernidade e antiguidade. A precariedade do moderno é também a condição para a sua avaliação: "assim que vê seus direitos conquistados, a modernidade expira. Então será posta à prova. Após sua extinção, verificar-se-á se algum dia pode ou não tornar-se antiguidade". Poder, um dia, ser lido como um autor antigo supunha um compromisso de construção de sua atualidade como heróica: "que a modernidade mereça um dia se tornar antiguidade" era o imperativo da arte em Baudelaire.

Para Benjamin, a visão alegórica é própria das épocas de desvalorização do mundo dos fenômenos, como no século XVII barroco. No século XIX, esta desvalorização tem causas e formas muito particulares. O sentimento de catástrofe permanente, o spleen, encontra na melancolia heróica de Baudelaire uma resposta: a sua poesia como "mimese da morte". A "mimese da morte" é a expressão radical do sentimento de transitoriedade pelo qual o moderno é aproximado do antigo. Benjamin nos fornece a imagem espacial desta proximidade: a Paris destruída pelas reformas urbanas de Haussmann revelando nas ruínas a sua caducidade. Como a passante de luto, que suscita em um só movimento a paixão e a perda, a edificação da moderna Paris revela a morte em seus escombros. A modernização da cidade faz aparecer sua antiguidade e torna $\mathrm{Pa}$ ris alegórica. No poema "Le Cygne", a melancolia do poeta diante de Paris em ruínas encontra sua forma clássica: sua angústia é a de Andrômaca no exílio. Na velha Paris destruída, nas obras das no- 
vas avenidas que se abrem, revela-se a verdade do moderno como catástrofe e morte. Para Benjamin, o poema - exemplar do procedimento alegórico - é a forma da teoria da modernidade de Baudelaire: por uma correspondência com a antiguidade, a imagem clássica do exílio de Andrômaca, o poeta dá forma ao seu exílio na Paris moderna, e, mais do que isto, dá forma ao exílio da experiência lírica na modernidade. "O movimento do Cygne", escreve, "é a de um berço que se balança entre a modernidade e a antiguidade". *A imagem da dor de Andrômaca, chorando seu luto e seu exílio junto aos simulacros da sua terra natal, é a lembrança inicial do procedimento alegórico que tornará clássica a vivência do choque do poeta ao atravessar o Carrossel transformado pela modernização da cidade. Seu exílio e luto ganham, por esta correspondência, a dolorosamente bela expressão: "Le vieux Paris n'est plus (la forme d'une ville /change plus vite, hélas! Que le coeur d'um mortel).

É pela alegoria que Baudelaire põe a modernidade à distância e, ironicamente, a torna "clássica": "A modernidade em Baudelaire é uma conquista; possui uma armadura" (...) "A alegoria é a armadura da modernidade". " Na construção das alegorias, Baudelaire calcula cada efeito da linguagem, do ritmo, da versificação. O que Benjamin encontra de desconcertante nessas alegorias é que Baudelaire as destitui do tom elevado da lírica convencional e lhes dá o ambiente prosaico de sua poesia. Nela, ele faz irromper inesperadas palavras de proveniência urbana, imagens banais do cotidiano. A sua técnica, considera Benjamin, é a do conspirador: surpresa, agilidade, choque: combinação do "estilo literário de Racine" com o estilo de um "jornalista do Segundo Império".

Elemento alegórico, o spleen transforma todo presente em antiguidade, em realidade frágil da qual, no próximo instante, só subsistem as ruínas. As águas-fortes de Meryon, tão admiradas por Baudelaire, mostram Paris simultaneamente em ruínas, em escombros, e em construção. A verdadeira natureza da modernidade é a experiência da transitoriedade e da morte. Representar a modernidade - em toda essa dimensão intangível do que possa significar representar o presente - só se torna possível por uma mortificação alegórica que destrói a sua fenomenalidade cronológica. Neste ato violento, instaura-se uma outra temporalidade, intensiva, que permite a conexão do presente à antiguidade. A heroificação do presente na poesia de Baudelaire depende do gesto destruidor da alegoria.
* (BENJAMIN, W. Das Passagen-Werk, Gesammelte Schriften, V, Frankfurt am Main: Suhrkamp Verlag, 1977. Paris Capitale du XIX siècle. Le livre des Passages. Paris: Ed. Du Cerf, 1989: J, 72-5)

"(BAUdELAIRE, Charles. "Les Fleurs du Mal". Em Oeuvres Complètes. Bibliothèque de la Pléiade. Paris: Éditions Gallimard, 1976: I, 85)

"(BENJAMIN, W. "Parque Central". Op. cit.: 155)

"(BENJAMIN, Walter. "Paris do Segundo Império". Op. cit.: 97) 


\section{Kátia Muricy}

É professora do Departamento de Filosofia da PUC-RJ e pesquisadora do CNPq. Fez Mestrado e Doutorado em Filosofia na Universidade de Louvain, Bélgica. Defendeu tese de Doutorado no Instituto de Filosofia da UFRJ e fez pós-doutorado na Universidade de Paris X. Co-autora de Danação da Norma (Graal), Os Sentidos da Paixão (Companhia das Letras), O Olhar (Companhia das Letras). É autora de A Razão Cética (Companhia das Letras) e de Walter Benjamin - Alegorias da Dialética (Relume Dumará).

\section{Resumo}

Palavras-chave: Modernidade; Alegoria; Crítica alegórica; Michel Foucault; Charles Baudelaire; Walter Benjamin
A visão de modernidade de Baudelaire é encontrada por Walter Benjamin na ótica do procedimento crítico alegórico: a mortificação da obra literária. É pela reciprocidade alegórica entre o poeta e o crítico que se evidenciam as mais ricas implicações dessa visão, que, para Benjamin, não está nos ensaios estéticos mas em Les Fleurs du Mal. Michel Foucault, reconhecendo o caráter alegórico da literatura contemporânea depois de Mallarmé, ignora a obra de Baudelaire. Não assumindo a contrapartida alegórica na sua própria leitura, Foucault perde, nos limites da arqueologia dos anos 1960, a mais rica expressão da modernidade em Baudelaire. Quando, posteriormente, reconhece a importância da concepção de modernidade do poeta, restringe-se a considerar os ensaios estéticos, aqueles que, na opinião de Benjamin, constituem o "ponto mais fraco" desta visão. 
Abstract

Walter Benjamin had an allegorical approach to analyse the vision of modernity inscribed in Baudelaire's poetry. The allegorical mode proceeds by way of "the mortification of the literary work". There are allegorical similarities between Benjamin's writings as a literary critic and Baudelaire's poetical work. For Benjamin, the most productive implications of Baudelaire's conception of modernity are to be found in the poems of The Flowers of Evil, not in Baudelaire's critical essays. In contrast with Benjamin, Michel Foucault, who recognized the allegorical character of contemporary literature after Mallarmé, was not interested in the poetical work of Baudelaire. This lack of interest can be explained by Foucault's refusal to have allegorical approach himself. So he loses, in the limits of "archaeology" of the sixties, the richest expression of modernity. Later, Foucault recognizes the importance of Baudelaire's view of modernity, but still considers only his aesthetic reflections, not his poetry. For Benjamin, "in Baudelaire's view of modernity, the theorie of modern art is the weakest point".

\section{Résumé}

C'est à partir d'une critique allégorique, entendue comme mortification de l'oeuvre littéraire, que Walter Benjamin trouve chez Baudelaire une théorie de la modernité. La réciprocité allégorique entre le poète et le critique met en évidence les plus fécondes conséquences de cette théorie qui, selon Benjamin, ne se trouve pas dans les essais esthétiques mais dans Les Fleurs du Mal. Michel Foucault, tout en reconnaissant le caractère allégorique de la littérature contemporaine depuis Mallarmé, ignore l'oeuvre de Baudelaire. Dans la mesure où il n'adopte pas la contrepartie allégorique de sa lecture, Foucault perd, dans les limites de l'archéologie des années 1960, la plus riche expression de la modernité de Baudelaire. Quand il reconnaît l'importance de la vision de modernité du poète, il ne considère que ses essais esthétiques, lesquels constituent, selon Benjamin, l'aspect le plus faible de cette vision.
Key words: Modernity; Allegory; Allegorical criticism

Mots-clés: Modernité; Allégorie; Critique allégorique; Michel Foucault; Charles Baudelaire; Walter Benjamin
Recebido em 19/04/2007

Aprovado em 12/06/2007 